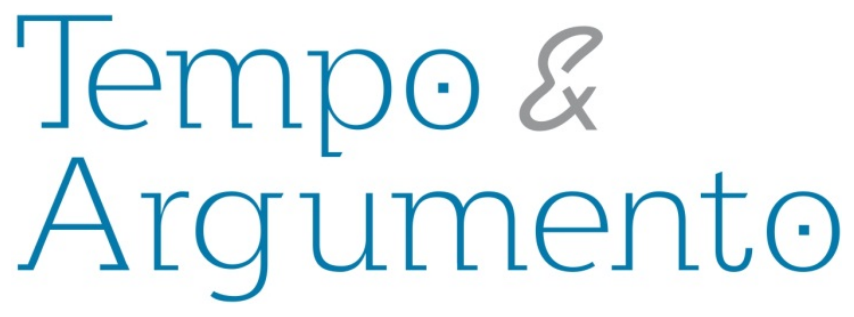

\title{
Um inventário histórico de estórias inventadas
}

\section{Resenha da obra:}

FAGUNDES, Bruno Flávio Lontra. As estórias a favor da História: as Efemérides Mineiras, de José Pedro Xavier da Veiga. Belo Horizonte: Fino Traço, 2014.

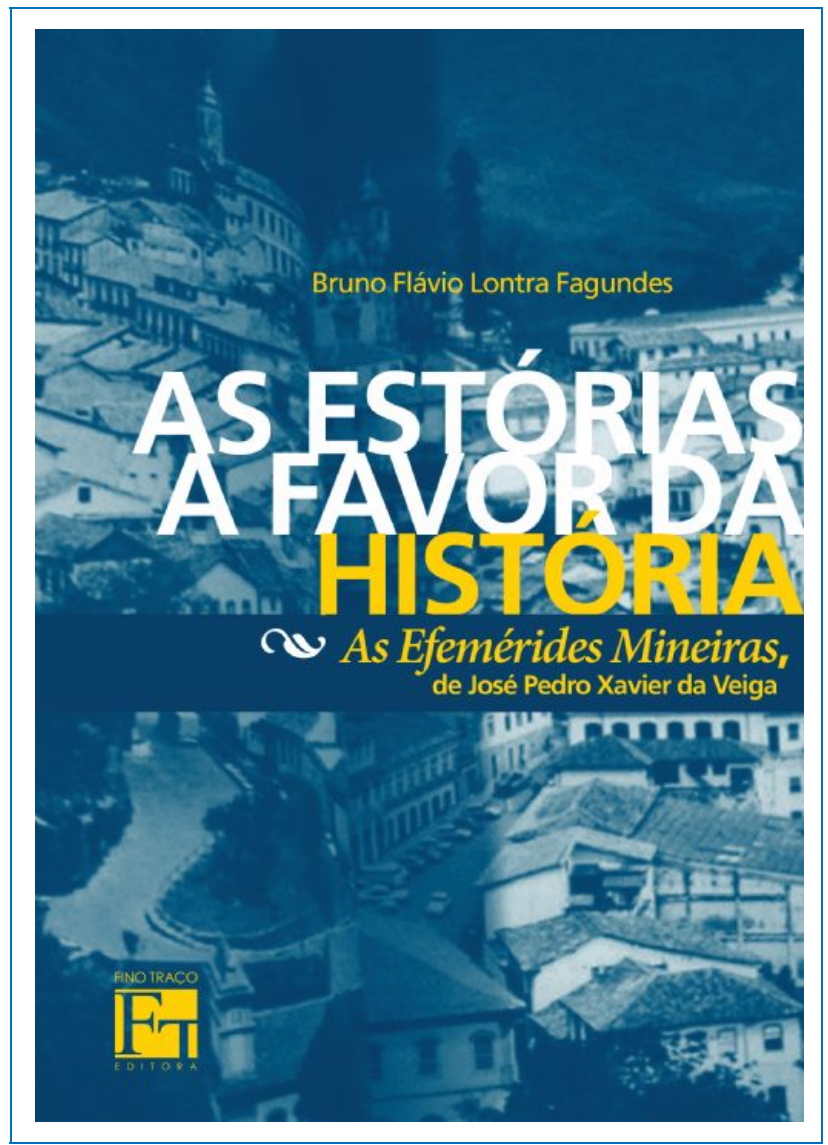

Autor da resenha

Carlos Gregório dos Santos Gianelli Doutorando no Programa de Pós-Graduação em História da Universidade do Estado de Santa Catarina. Brasil gianelli.87@hotmail.com

\section{Para citar esta resenha:}

FAGUNDES, Bruno Flávio Lontra. As estórias a favor da História: as Efemérides Mineiras, de José Pedro Xavier da Veiga. Belo Horizonte: Fino Traço, 2014. Resenha de: GIANELLI, Carlos Gregório dos Santos. Um inventário histórico de estórias inventadas. Revista Tempo e Argumento, Florianópolis, v. 9, n. 20, p. 339 - 343. jan./abr. 2017. 
A diferenciação entre o que é uma história verídica e o que seria uma ficção muitas vezes já é sinalizada no uso da palavra. Para citar o exemplo na língua inglesa, o story (estória) se apresenta quase sempre que uma ficção quer se fazer explícita em oposição à palavra history (história), que se trata do estudo, análise ou até mesmo relato de algum fato ocorrido. Na língua portuguesa praticada no Brasil essa diferenciação existe em nosso vocabulário, mas, vem sendo cada vez menos utilizada. Ao se checarem livros ou coleções mais antigas, as estórias em contraposição às histórias estão presentes. No entanto, a palavra estória vem caindo em desuso sendo que a história tem servido tanto para a dita ficção como para a realidade. Não é à toa que o título do livro de Bruno Flávio Lontra Fagundes faz uso desse jogo de palavras ao tratar do tema proposto. "As estórias a favor da História: As Efemérides Mineiras de José Pedro Xavier da Veiga" tem como um de seus objetivos e fio condutor refletir sobre essa tensão presente entre a ficção e realidade na tessitura das narrativas históricas. Historiador de formação, Fagundes buscou nesse trabalho, que resultou em sua dissertação de Mestrado defendida junto ao Programa de Pós-Graduação em Letras (Estudos Literários), da Faculdade de Letras da UFMG, aproximar duas áreas que muitas vezes foram consideradas totalmente opostas no campo da escrita: as estórias e as histórias.

Como indicado no título, o livro analisa a obra "As Efemérides Mineiras”, de José Pedro Xavier da Veiga, publicada em Minas Gerais no ano de 1897. Trata-se de um livromonumento com mais de mil e oitocentas páginas, dividas em quatro volumes, que busca fazer um levantamento da história da província de Minas Gerais de 1733 a 1892. Torna-se válido ressaltar que o próprio termo efeméride é pouco utilizado hoje, e cabe a breve explicação de que se trata do registro de algo importante que aconteceu em um dia específico. Levando-se isso em consideração, fica um pouco mais clara a organização proposta por Xavier da Veiga em seu livro-monumento. As efemérides não estão organizadas ano após ano, mas dia após dia. Essa primeira característica a ser observada logo no índice do livro já abre um espaço interessante de reflexão a respeito da organização cronológica e temporal que é proposta nessa obra do final do século XIX. Fagundes ressalta que essa característica não era comum de outras efemérides realizadas na mesma época. Sendo assim, Xavier da Veiga propõe uma organização da história 
diferente deseus contemporâneos, tendo os anos como esteira condutora dos acontecimentos históricos. Nas "Efemérides Mineiras", temos um calendário que parte de $1^{\circ}$ de janeiro a 31 de dezembro, cobrindo não somente um ano, mas quase três séculos. Nesse sentido, teríamos a organização mais ou menos desta maneira, como indica Fagundes: “1 de janeiro 1733 (...) 1740 (...) [...] 2 de janeiro 1807 (...) 1811 (...).”

O livro de Bruno Fagundes, a respeito da obra de Xavier da Veiga, se organiza da seguinte maneira: antes de fazer a sua análise das Efemérides, Fagundes mostra a apresentação que o próprio José Pedro Xavier da Veiga faz de sua obra monumental. $O$ prefácio da obra de Xavier da Veiga contém desde instruções de como realizar a leitura, até uma espécie de pedido de desculpas pelas lacunas temporais presentes. Por se tratar de uma obra datada do ano de 1897, está inserida no contexto pós-republicano em que se buscava de todo modo "re-fundar" um novo país sob a égide dos novos ideais positivistas, materializados no lema ordem e progresso. Não se tratava apenas de buscar uma brasilidade moderna que fundamentasse as aspirações republicanas, mas de organizar a história do país muito mais por inventários documentais, como as efemérides, do que por outro tipo de produção historiográfica ou memorialística. Xavier da Veiga além de ser o autor das Efemérides foi o primeiro diretor do Arquivo Histórico Mineiro, o que denota o caráter depositário que a obra possuía para ele. Para Xavier da Veiga não se tratava apenas de contar estórias, mas de se guardar e, até mesmo, preservar a história.

Após a apresentação do livro, “Por ele mesmo”, Bruno Flávio Lontra Fagundes adentra a obra sempre mostrando algo que lhe sobressai e uma possível análise a ser realizada. Nos próximos três capítulos após a apresentação do livro pelo próprio Xavier da Veiga, Fagundes analisa três questões em que dedica um capítulo para cada: temporalidades; memória; e a própria noção de invenção da História que acaba suscitando das Efemérides.

Adiante, no livro, Fagundes analisa em seu quinto capítulo como Xavier da Veiga lidava com a carga documental que recebia de várias partes do estado de Minas Gerais para a realização da obra; é neste momento que o título dado por Fagundes faz-se presente: "As estórias a favor da História". Este que poderia até mesmo ser um lema adotado por Xavier da Veiga na compilação de documentos e testemunhos. $\mathrm{O}$ arquivista 
mineiro considerava importante desde os documentos oficiais, como decretos-lei, até relatos de casos estranhos como alguns títulos indicam: "diamante achado por um preto; grandioso meteoro; um esqueleto monstro, etc." Como já foi dito, o cargo de administrador do Arquivo Histórico Mineiro vai conferir a Xavier da Veiga a responsabilidade de salvaguardar todos os retalhos de história que the são enviados. Anexos aos documentos que chegam para ele estão presentes, muitas vezes, bilhetes pedindo para que o pacote seja preservado, ressaltando a preciosidade daquele documento em questão. Tal cuidado que o arquivista e escritor mineiro possuía com os documentos que aos quais tinha acesso permeia toda a obra das Efemérides, assim como a função social do devir histórico que lhe é incumbido.

É dentro dessa questão que Fagundes, em seu sexto capítulo, lança a reflexão voltada à autoria das Efemérides. Seria apenas José Pedro Xavier da Veiga o autor de um livro que conta com tantas páginas resultantes de dezoito anos de trabalho? Qual a parcela de contribuição das centenas de anônimos que enviaram seus relatos e documentos para a realização desta empreitada? Tais reflexões cabem tanto para Fagundes, ao analisar as Efemérides, como para qualquer historiador que tenha contato com obras grandiosas, ou que no momento de tecer a sua própria narrativa histórica reflita sobre o lugar dos documentos e testemunhos em sua produção.

Em seu sétimo capítulo, é feita uma análise a respeito da figura do próprio José Pedro Xavier da Veiga, que além de ter ocupado o cargo de primeiro diretor do Arquivo Histórico Mineiro, também foi deputado, vinha de uma família de letrados que chegaram a ser proprietários de livrarias e possuía grande respeito justamente por ser apontado como um dos guardiões da história de Minas Gerais. No oitavo e último capítulo, Fagundes trabalha a relação entre Xavier da Veiga e o seu livro, mostrando como determinadas obras além de monumentalizar os personagens retratados nela podem enaltecer seus autores. Xavier da Veiga é destacado no imaginário social pela grande empreitada de memória e identidade mineira que constituiu suas Efemérides.

Por fim, cabe ressaltar a importância que o livro “As Estórias a favor da História: As Efemérides Mineiras de José Pedro Xavier da Veiga”, de Bruno Flávio Lontra Fagundes tem para o campo da História. As questões que o autor levanta, aproximando os campos 
dos estudos literários e da teoria da história são de grande relevância para aquele pesquisador que busca uma perspectiva interdisciplinar para o seu trabalho que acaba, em muitos casos, levando a uma reflexão mais profunda acerca do tema pesquisado. Poderíamos, por fim, elencar os seguintes temas como muito importantes para o fazer historiográfico que são problematizados pelo autor: a questão da memória de um povo; o desafio da delimitação das temporalidades (tendo em vista a característica peculiar de organização temporal das efemérides que reverbera em sua narrativa histórica); o tratamento dado para um grande acervo documental; a função social exercida por Xavier da Veiga enquanto historiador mineiro; reflexões a respeito da autoria das efemérides (como podemos afirmar que Xavier da Veiga é o único autor de um livro composto por centenas de contribuições e relatos? Como podemos pensar nessa mesma problemática na tessitura de nossos trabalhos historiográficos?) e, por fim, a relação entre autor e obra. Fagundes analisa com bastante seriedade um livro que se porta como monumento histórico e não apenas como uma narrativa histórica.

Recebido em 08/09/2016 Aprovado em 09/03/2017 